\title{
Diagnosis of urinary schistosomiasis among primary school pupils in Patigi local government: Haematuria Vs Microscopy
}

\author{
*Aderibigbe S.A. ${ }^{1}$, Okpareke Okechukwu ${ }^{1}$, Adaramola S.O. ${ }^{2}$
}

\begin{abstract}
Objectives: To establish the reliability of haematuria in diagnosing Urinary Schistosomiasis infection.

Methodology: The research was a cross sectional study. Information on demographic characteristics and history of haematuria was collected from 2000 primary school pupils aged 5-15 years. Urine samples were collected for microscopy. The data from completed questionnaires were sorted and edited manually to detect omissions and error. Analysis of data was done using SPSS software version 20.0 (Statistical Package for Social Sciences) using simple frequency counts, sensitivity and specificity analysis and chi square test.
\end{abstract}

Results: Prevalence of Schistosomiasis by haematuria was 34.5\% while that of microscopy was $35 \%$. Diagnosis by haematuria compared to microscopy had $94.7 \%$ sensitivity and a specificity of $97.6 \%$. About $94.6 \%$ of urine samples that were positive for haematuria were also positive for ova of Schistosoma haematobium on microscopy. The two diagnostic methods for urinary schistosomiasis showed strong positive relationship $(\mathrm{p}<0.001)$. Visible haematuria alone and history of haematuria alone had high positive predictive value $(99.1 \%$ and $85 \%$ respectively) in diagnosis of urinary schistosomiasis.

Conclusion: This study has shown that haematuria is as good as microscopy in diagnosing urinary schistosomiasis in endemic areas and should be used routinely.

Keywords: Diagnosis, Haematuria, Microscopy, Urinary schistosomiasis, Patigi

\footnotetext{
*Corresponding author

Aderibigbe S.A.

http://orcid.org/0000-0002-4633-858X

Email:tayonov23@yahoo.com

${ }^{1}$ Department of Epidemiology \& Community Health, University of Ilorin, Ilorin, Nigeria.
${ }^{2}$ Department of Epidemiology \& Community Health, University of Ilorin Teaching Hospital, Ilorin, Nigeria.
} 


\title{
Diagnostic de la schistosomiase urinaire chez les Élèves d'ecole primaire dans le gouvernement local de Patigi: Hématurie contre La Microscopie
}

\author{
*Aderibigbe S.A. ${ }^{1}$, Okpareke Okechukwu ${ }^{1}$, Adaramola S.O. ${ }^{2}$
}

\begin{abstract}
Résumé
Objectif de l'étude: Établir la fiabilité de l'hématurie dans le diagnostic urinaire schistosomiase infection.

Méthode de l'étude: La recherche était une étude transversale. Des informations ou des données sur les caractéristiques démographiques et l'histoire de l'hématurie ont été recueillies auprès de 2000 élèves d'école primaire âgés de 5 à 15 ans. Des échantillons d'urine ont été collectés pour la microscopie. Les données des questionnaires remplis ont été triées et éditées manuellement pour détecter des omissions et les erreurs. L'analyse des données a été réalisée à l'aide du logiciel SPSS version 20.0 (progiciel statistique pour les sciences sociales), à l'aide de simples comptages de fréquence, d'une analyse de sensibilité et de spécificité et d'un test du chi carré. (Chi Square Test)
\end{abstract}

Résultats: La prévalence de la schistosomiase par hématurie était de $34.5 \%$, tandis que, celle de la microscopie était de $35 \%$. Le diagnostic par hématurie comparé à la microscopie avait une sensibilité de 94.7\% et une spécificité de $97.6 \%$. Environ $94.6 \%$ des échantillons d'urine positifs pour l'hématurie étaient également positifs pour les ovules de Schistosomahaematobium au microscope. Les deux méthodes de diagnostic de la schistosomiase urinaire ont montré une relation positive et forte $(\mathrm{p}<0.001)$. La seul hématurie visible et de l'histoire de l'hématurie seul avait une valeur prédictive positive élevée ( $99.1 \%$ et $85 \%$, respectivement) dans le diagnostic de la schistosomiase urinaire.

Conclusion: Cette étude a montré que l'hématurie est aussi efficace que la microscopie pour diagnostiquer la schistosomiase urinaire dans les zones d'endémie et doit être utilisée systématiquement ou comme d'habitude.

Mots-clés : diagnostic, hématurie, microscopie, schistosomiase urinaire, syndrome de Patigi

\footnotetext{
*Auteur Correspondant

Aderibigbe S.A.

http://orcid.org/0000-0002-4633-858X

Email:tayonov23@yahoo.com

${ }^{1}$ Department of Epidemiology \& Community Health, University of Ilorin, Ilorin, Nigeria.

${ }^{2}$ Department of Epidemiology \& Community Health, University of Ilorin Teaching Hospital, Ilorin, Nigeria.
} 


\section{INTRODUCTION}

Schistosomiasis (also known as bilharziasis, snail fever, or Katayama fever) is a neglected parasitic tropical disease caused by a trematode of the genus schistosoma. It is one of the major public health problems facing developing countries (1). Schistosomiasis is mostly found in Asia, Africa, and South America in areas where the water contains fresh-water snails Bulinus that carry the parasite. Globally, over 600million people are at risk with over 200 million infections in 76 countries annually (2). Sub-Saharan Africa accounts for 93\% (192 million) of the world estimated 200 million cases of schistosomiasis. Nigeria tops the list of the highly endemic countries with an estimated 101.3 million at risk of infection and 29 million of the people being infected including 16 million children (3). This is closely followed by United Republic of Tanzania (19million), Ghana, and Democratic Republic of Congo (15 million) and Mozambique (13 million) making up the top five countries in Africa with schistosomiasis infection $(4,5)$. Primary school children are particularly vulnerable to Schistosomiasis because of their habit of playing in water, where they may contact the infestation. As such, they are the ideal target group to assess the reliability of haematuria in diagnosing urinary schistosomiasis.

Two forms of Schistosomiasis exist, the urinary and intestinal schistosomiasis. Schistosoma mansoni, japonicum, intercalatum and mekongi, affects the gastro-intestinal tract causing bloody stool and ascites, while Schistosoma haematobium affects the urinary tract presenting as haematuria as its classical symptom (1). Haematuria is a condition where urine has red blood cells (erythrocytes) present. It can be either idiopathic and/or benign and it can also signify the presence of renal stone or urinary tract tumour (kidneys, ureters, urinary bladder, prostate, and urethra), which can be trivial to lethal.

Two types of haematuria exist. Macroscopic haematuria (or "frank" or "gross" haematuria) which is when blood is visible in the urine sample, and microscopic haematuria when small amounts of blood, is seen only on urinalysis or light microscopy (6). It had been generally reported that the detection of micro haematuria had shown to be reliable in diagnosing urinary schistosomiasis. Though considering other possible causes of haematuria, caution must thus be taken in adapting this approach especially in schistosomiasis non endemic area (7). It had also been established that the reagent strip haematuria is a good indicator of $S$. haematobium infection that could be used repeatedly in areas endemic to urinary schistosomiasis where microscopy is not available (8). Furthermore, compared to micro haematuria and urine microscopy, a history of gross haematuria and visible bloody urine can also be used as a rapid diagnostic marker, specific for $S$. haematobium infestation in extremely resource-poor settings endemic to schistosomiasis where no microscopy and urine reagent strip are available (9). This study established the reliability of haematuria in diagnosing urinary schistosomiasis infestation among primary school pupils in Patigi Local Government Area, Kwara State.

\section{MATERIALS AND METHODS Description of Study Area}

This research work was conducted in selected primary schools in Patigi Local Government Area (LGA). Patigi is an ancient town in Kwara State, Nigeria, inhabited by the Nupe people. The Local Government is made up of three districts: Lade, Patigi and Kpada District (Figure 1). The Districts are divided into wards comprising of different communities. There are 44, 34 and 39 primary schools including 3, 6 and 1 private school in these districts respectively making a total of 117 primary schools in Patigi Local Government. The estimated population of primary school pupils according to patigi local government education authority 2014/2015 school's enrolment list is 20331 pupils. There are $7294,7952,5085$ primary school pupils in lade, patigi, and lade district respectively.

\section{Study Design \& Study Population}

The study was a cross-sectional survey carried out between March to July 2016 to establish the reliability of haematuria in diagnosing urinary schistosomiasis among primary school pupils aged 5-15 years in Patigi Local Government Area. Primary school pupils aged $5-15$ years who were duly registered in the public and private schools and were present as at the time of the study participated in the study for sampling. While those below the age of 5 years and above 15 years were not included in the study. Also excluded were those not present in school as at the time of sample collection and pupils that had taken praziquantel in the last six months.

\section{Sampling Technique}

A multi-stage sampling technique was used to select 2000 respondents from the study population. The sample size of 2000 respondents 
was proportionately allocated to the three district of Patigi Local Government Area based on the population of primary school pupils in each district. One third of the public primary schools in each district were selected by simple random sampling while there was purposive addition of private schools in each district to the selected public schools and proportionate allocation of the sample size for each district to the selected schools based on the population of each school. The population of primary school children in each school was stratified by sex and the desired sample size selected by systematic random sampling based on the proportion of male and female pupils.

\section{Data Collection and Analysis}

A standardized semi-structured interviewer administered questionnaire and sterile specimen bottle for urine sample collection for laboratory analysis were used for data collection. The questionnaire comprised of section on demographic information with history of passage of blood in urine.

Urine Sample Collection: About $10-15 \mathrm{ml}$ of terminal urine sample was collected into sterile, plastic universal containers between the hours of 10:00h - 14:00h on each collection day. Each sample collected was labelled with the exact identification numbers that appeared on the questionnaire form. Then urine samples were transported to the laboratory department of Patigi General Hospital for laboratory analyses.

Macroscopic Examination for Visible Haematuria: The urine samples were inspected one after the other for the presence of visible blood and the number of children presenting with visible blood in the urine was recorded.

Urine Examination for Micro Haematuria: The urine samples were tested for microhaematuria using urine reagent Strips [combi 9]. The reagent strip was dipped into the urine contained in a sterile bottle for 5 seconds. The change in strip colour was compared with the colour chart of the manufacturer to approximate the amount of blood in the urine. And results were recorded as negative, trace,,+++ or +++ as per manufacturer recommendations. A strip result of +1 or more was considered as a positive indicator for haematuria.

Microscopic Examination for Schistosoma Haematobium Ova by Sedimentation Method: Centrifugation of Ten (10) $\mathrm{ml}$ of the urine samples was done for 5 minutes at $5000 \mathrm{rpm}$. The sediment left after discarding supernatant is transferred to a clean grease-free glass slide's centre after which a cover slip was added. This was placed on a light microscope and examined using a $\times 40$ objective to identify Schistosoma haematobium ova identified by a terminal spine. Urine samples containing $\operatorname{egg}(\mathrm{s})$ of $S$. haematobium and those without eggs were recorded.

\section{Data Processing and Analysis}

The data from completed copies of questionnaire were sorted and edited manually to detect omissions and error. Data was analysed, using SPSS software version 20.0 (Statistical Package for Social Sciences). Data were presented in tables, charts and percentages. Chisquare was used to compare differences and association between variables. Differences and associations were considered significant at a $p$ value of $<0.05$.

\section{Ethical Approval}

Ethical approval for this study was gotten from the Ethical Review Committee of University of Ilorin before the start of the study. Permission was also obtained from the Health and Education Departments of Patigi LGAs where the study was carried out. Permission was gotten from the village head of the participating communities where the primary schools were located before the commencement of the study. Oral informed consent was gotten from parents through the Parents Teachers Associations of the respective schools. Informed consent was obtained verbally from the respondent before administering the questionnaire and participation by pupils was voluntary. Information collected from participants was maintained with utmost confidentiality as names were absent on the forms and samples but codes.

\section{RESULTS}

Out of the 2000 respondents, 691 were positive for haematuria giving a prevalence of $34.5 \%$. While $232(11.6 \%)$ of the respondents with haematuria had visible haematuria, 459 $(22.9 \%)$ respondents were positive for micro haematuria (Table 1). Though the prevalence of haematuria varies slightly across the various age groups and sex, the differences were not statistically significant. Similarly, out of the 2000 respondents, 697 (35\%) were positive for S. haematobium ova. Though the prevalence of Schistosomal Ova varies slightly across the various age groups and sex, the differences were 
not statistically significant (Table 1).

The microscopy of urine sediments showed that $35 \%$ of subjects were positive for ova of S. haematobium (Table 2), while the test for haematuria yielded a prevalence of $34 \%$ (Table 1). However, $94.6 \%$ of urine sample that were positive for haematuria were positive during microscopy for ova of Schistosoma haematobium (Table 3). Analysis of the result showed that haematuria compared to parasitological detection of $S$. haematobium indicated a sensitivity of $94.7 \%$, specificity $97.6 \%$, positive predictive value $94.6 \%$, and negative predictive value $97.2 \%$. Hence the two diagnostic methods for urinary schistosomiasis (i.e. microscopic examination of urine sediments and haematuria) showed strong positive relationship. $(\mathrm{p}<0.001)$. (Figure 2$)$.

Of the 232 pupils that had visible haematuria, $99.1 \%$ of them were positive for S. haematobium. Of the 221 pupils that admitted history of blood in urine, $85 \%$ were positive for S. haematobium (Table 3 ).

\section{DISCUSSION}

The prevalence of haematuria by dipstick observed in the study showed a strong positive relationship with the observed prevalence of microscopy for ova of $\mathrm{S}$. haematobium (34\% vs $35 \%)$. About $94.6 \%$ of urine samples that were positive for haematuria by dipstick were observed to be positive for microscopy for ova of S. haematobium showing a strong positive predictive ability of haematuria by dipstick in diagnosing urinary schistosomiasis. Similarly, about $97.2 \%$ of urine samples that were negative for haematuria were also negative for microscopy for ova of $\mathrm{S}$. haematobium showing a strong negative predictive ability of absence of haematuria by dipstick in detecting those without urinary schistosomiasis. Further analysis of the result showed that the detection of haematuria by dipstick as a diagnostic tool for urinary schistosomiasis has a high sensitivity and specificity of $95 \%$ and $98 \%$ respectively. However, a statistically significant association was found between schistosoma infection and haematuria detection by dipstick, hence haematuria by dipstick is highly significant in diagnosing urinary schistosomiasis in Patigi Local Government where it is endemic. These support the general assertion that haematuria by dipstick is a good marker for S. haematobium infection in endemic area. In 1983, the World Health Organization (WHO) in association with the Health Ministries of several endemic countries (Botswana, Egypt, Madagascar, Mauritius and Zanzibar) launched a massive programme to assess control methods of urinary schistosomiasis (10). The findings of this programme included a suggestion/conclusion that a simple and rapid test for blood in the urine is more reliable than microscopic examination, which can prove difficult in the field (10). Celestine et al in his study established a strong positive correlation between haematuria (combination of macro haematuria and micro haematuria) and microscopic diagnosis for urinary schistosomiasis (11). Similar study by Adeyemi et al established that the reagent strip for haematuria is a good indicator of $S$. haematobium infection that could be used repeatedly in areas endemic for urinary schistosomiasis where microscopy is not available (8).

However, the findings of this study is in contrast with the reports of Sam-wobo et al who stated that positive haematuria may not necessarily signify the presence of urinary schistosomiasis in a study conducted in nonendemic area of Abeokuta, Nigeria, where they observed that most pupils that tested positive for micro haematuria $(6 \%)$ using the reagent strip were higher than those who were actually infected with the disease (3.6\%) (7). This however calls for caution when using haematuria results to diagnose urinary schistosomiasis especially in Schistosoma non-endemic Areas. Micro haematuria was found to vary across the various age groups and sex with no statistically significant difference. Similar trends were also observed with microscopy for ova of $\mathrm{S}$. haematobium. This could further substantiate the strong positive relationship that exist between the two diagnostic methods.

Furthermore, out of the 232 pupils that had visible haematuria, 230 pupils were positive for ova of $\mathrm{S}$. haematobium giving visible haematuria a $99.1 \%$ positive predictive ability. Similarly, out of 221 pupils that gave history of haematuria, 186 pupils were positive for ova of S. haematobium giving history of haematuria $85 \%$ positive predictive ability. Therefore, the presence of visible blood in urine and history of haematuria can also be used as specific rapid diagnostic markers for S. haematobium infection in extremely resource-poor settings endemic to schistosomiasis where no urine reagent strip is available. Savioli et al in their study stated that if a person shows visible haematuria in an area endemic for S. haematobium, there is no need for 
further diagnostic investigation of that person (12). Inyang-Etoh et al in their study established that self-diagnosis with the aid of gross haematuria was a reliable diagnostic tool for diagnosing urinary schistosomiasis (9). Furthermore, this ascertains the fact that whenever there is a report of gross haematuria especially in urinary schistosomiasis endemic community, it is usually associated with urinary schistosomiasis. Self-diagnosis based on haematuria can hence be used as a basis for diagnosing urinary schistosomiasis infection in an endemic community where microscopy and reagent strips are not available.

While microscopy remains the gold standard for the diagnosis of urinary schistosomiasis, this study has shown that micro haematuria by dipstick can be used with high degree of certainty in the diagnosis of urinary schistosomiasis in endemic areas where microscopy is not feasible. However, in poor resource setting where dipstick for micro haematuria is not available, visible haematuria and history of blood in urine can serve as a reliable alternative in diagnosing urinary schistosomiasis.

Acknowledgements: The authors wish to thank all the pupils that participated in this study and their parents for giving their children the permission to participate.

Conflict of interest: The authors declare no conflict of interest.

\section{REFERENCES}

1. Chitsulo L, Engels D, Monstesor A, Savioli L. The global status of schistosomiasis and its control. Ada Trop. 2000 Oct; 77:41-45.

2. World Health Organization. Report of WHO informal consultation on Schistosomiasis control. World Health Organization, Geneva 1999.

3. Hotez PJ, Kamath A. Neglected tropical diseases in sub-Saharan Africa: review of their prevalence, distribution and disease burden. PLoS Negl Trop
Dis. 2009; 3: 412.

4. Okoli EI, Odabido AB. Urinary schistosomiasis among school children in Ibadan, an Urban Community in South-Western Nigeria. Trop Med Int Health. 1999; 4(4):308-315.

5. World Health Organization. Prevention and Control of Schistosomiasis and Soil transmitted Heminthiasis. WHO Technical Report. Series No 912i-vi: World Health Organization Geneva 2002.

6. Spetie DN, Nadasdy T, Nadasdy G, et al. "Proposed pathogenesis of idiopathic loin painhaematuria syndrome". American Journal of Kidney Disease. 2006 March, 47 (3): 419-27.

7. Sam-Wobo SO, Ajayi TO, Ijaduola T, et al. Status of urinary schistosomiasis among Primary School Children in Abeokuta, Nigeria. International journal of medicine and medical sciences. mar 2013.vol 5 pp106-109

8. Adeyemi E, Aisien M.S.O. and Sam-wobo S.O. Evaluation Of Questionnaire, Reagent Strip And Egg Count As Diagnostic Techniques For Confirming Urinary Schistosomiasis in School Children, Edo State, Nigeria. Nigerian journal of parasitology. 2014. 35 pp 47-52.

9. P Inyang-Etoh, J Author, A Eyo, V Usanga. Self Diagnosis as a Possible Means of Diagnosing Urinary Schistosomiasis among School Children in an Endemic Community in Nigeria. The Internet Journal of Tropical Medicine. 2009. Vol. 7 (1), pp. $1-5$

10. Chidozie EU, Daniyan SY. Urinary schistosomiasis epidemiological survey of Urinary Schistosomiasis among Children in selected Schools: A preliminary study in Minna, Nigeria African Journal of Biotechnology. 2008 august. Vol. 7 (16), pp. 2773-2776.

11. Celestine CO, Geme UD, Emeka IN, Gilbert M, Innocent EN, Nkiru A. Comparative analysis of urinary schistosomiasis among primary school children and rural farmers in Obollo-Eke, Enugu State, Nigeria: Implications for control. Asian Pacific Journal of Tropical Medicine 2012, 796802.

12. Savioli L, Hatz C, Dixon H, Kisumku UM, Mott KE. Control of morbidity due to Schistosoma Haematobium on Pemba Island: Egg excretion and Haematuria as indicators of infection. American Journal of Tropical Medicine and Hygiene. 1990, 43 (3) $289-295$ 
Table 1: Detection of haematuria and its distribution by age group and gender

\begin{tabular}{|c|c|c|c|c|c|}
\hline \multirow[t]{2}{*}{ Variable } & \multicolumn{3}{|l|}{ Haematuria } & \multirow[b]{2}{*}{$\chi^{2}$} & \multirow[b]{2}{*}{$P$ value } \\
\hline & Positive (\%) & Negative (\%) & Total & & \\
\hline Visible Haematuria & $232(11.6)$ & $1768(88.6)$ & 2000 & & \\
\hline Micro Haematuria & $459(22.9)$ & $1309(77.1)$ & 1768 & & \\
\hline Total Haematuria & $691(34.5)$ & $1309(65.5)$ & 2000 & & \\
\hline \multicolumn{6}{|l|}{ Age Groups } \\
\hline $5-7$ & $186(34.7)$ & $350(65.3)$ & 536 & \multirow{4}{*}{7.513} & \multirow{4}{*}{0.057} \\
\hline $8-10$ & $304(32)$ & $646(68)$ & 950 & & \\
\hline $11-13$ & $161(39.4)$ & $248(60.6)$ & 409 & & \\
\hline$\geq 14$ & $40(38.1)$ & $65(61.9)$ & 105 & & \\
\hline \multicolumn{6}{|l|}{ Gender } \\
\hline Male & $279(31.4)$ & $604(68.6)$ & 883 & \multirow{2}{*}{6.098} & \multirow{2}{*}{0.054} \\
\hline Female & $412(36.9)$ & $705(63.1)$ & 1117 & & \\
\hline
\end{tabular}

Table 2: Microscopic detection of ova of S. Haematobium and its distribution by age group and gender.

\begin{tabular}{|c|c|c|c|c|c|}
\hline \multirow[b]{2}{*}{ Variable } & \multicolumn{3}{|c|}{ Urinary Schistosomiasis } & \multirow[b]{2}{*}{$\chi^{2}$} & \multirow[b]{2}{*}{ P value } \\
\hline & Positive (\%) & Negative (\%) & Total & & \\
\hline $\begin{array}{l}\text { Schistosoma } \\
\text { Ova. }\end{array}$ & $697(35 \%)$ & $1303(65 \%)$ & 2000 & & \\
\hline \multicolumn{6}{|l|}{ Age Groups } \\
\hline $5-7$ & $187(34.9)$ & $349(65.1)$ & 536 & \multirow{4}{*}{4.849} & \multirow{4}{*}{0.183} \\
\hline $8-10$ & $312(32.8)$ & $638(67.2)$ & 950 & & \\
\hline $11-13$ & $159(38.9)$ & $250(61.1)$ & 409 & & \\
\hline$\geq 14$ & $39(37.1)$ & $66(62.9)$ & 105 & & \\
\hline \multicolumn{6}{|l|}{$\overline{\text { Gender }}$} \\
\hline Male & $404(36.2)$ & $713(63.8)$ & 1117 & \multirow{2}{*}{1.937} & \multirow{2}{*}{0.164} \\
\hline Female & $293(33.2)$ & $590(66.8)$ & 883 & & \\
\hline
\end{tabular}

Table 3: Comparison between hematuria and microscopic detection of ova of S. Haematobium.

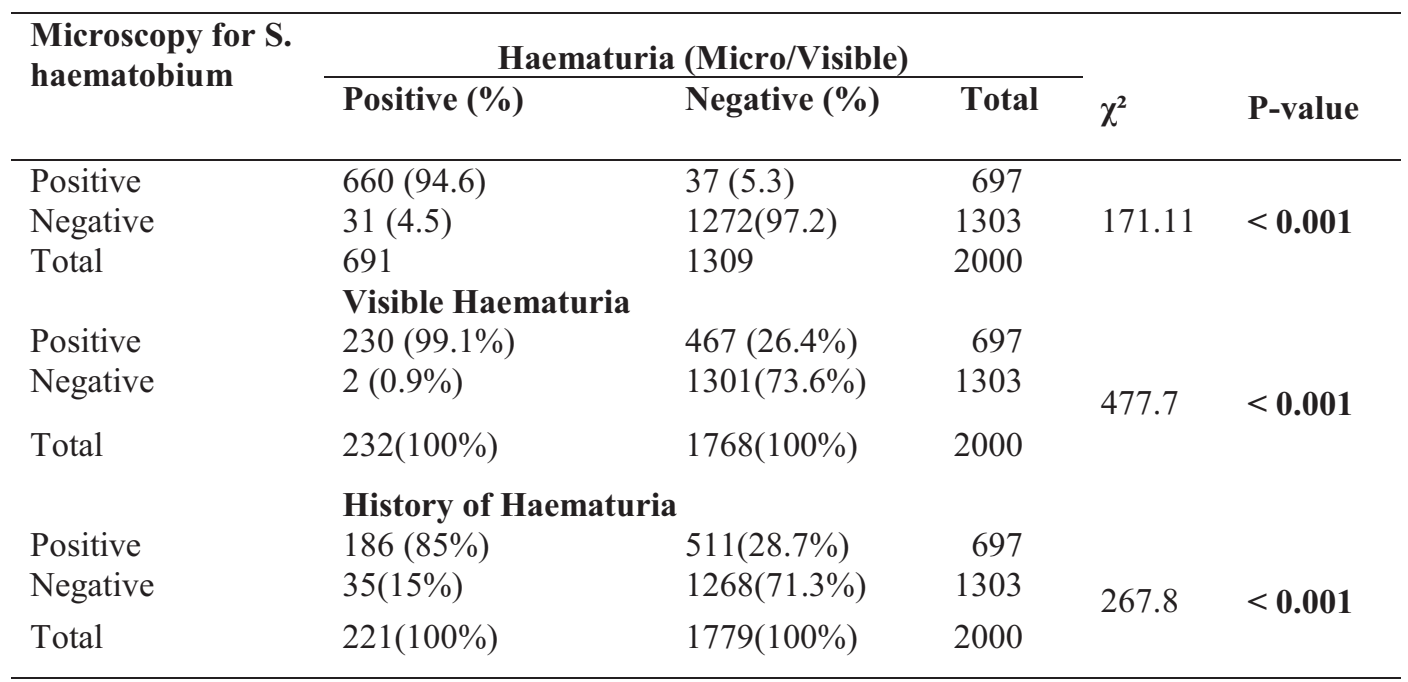




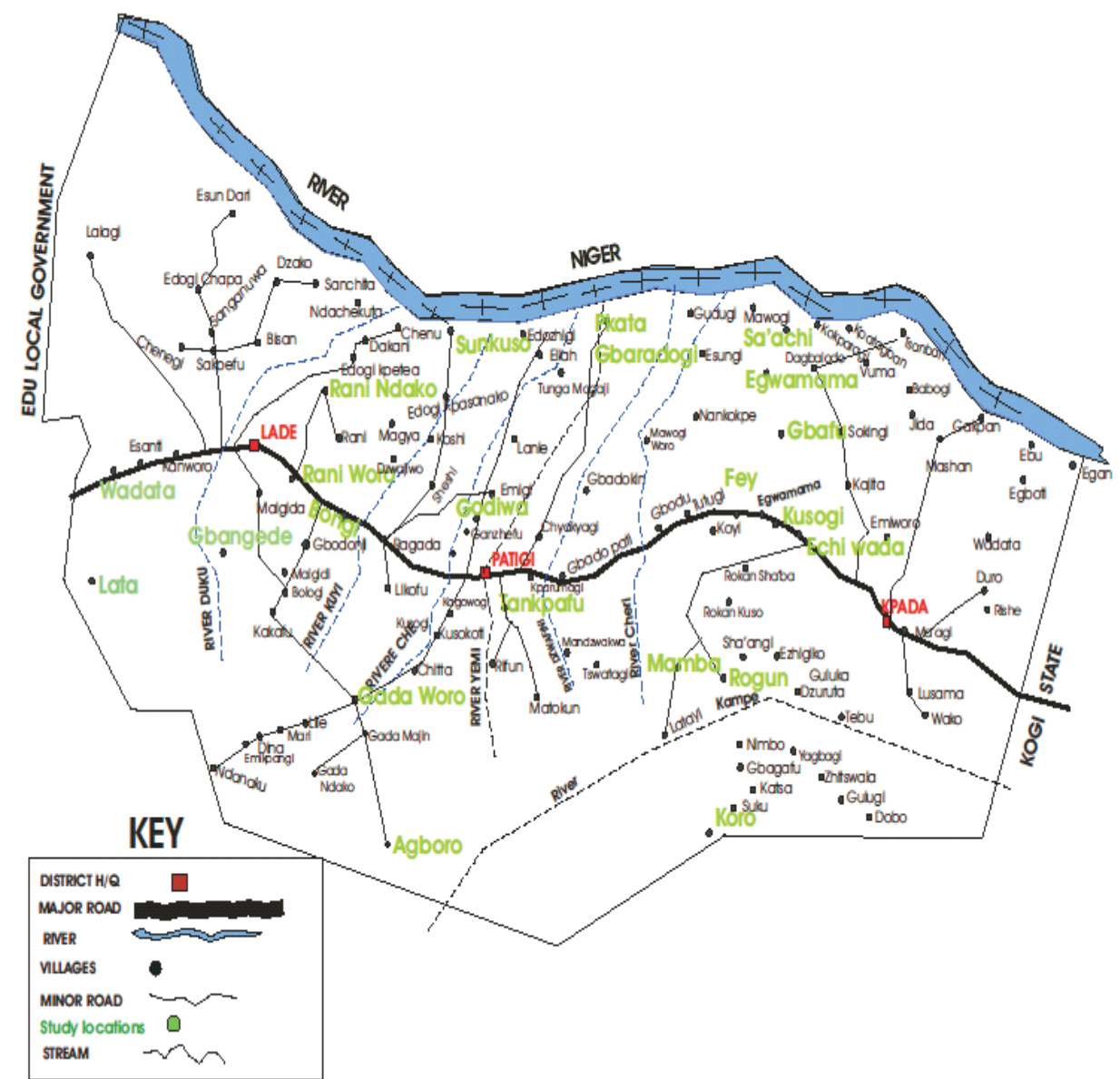

Figure 1: Map of Patigi local government area showing the boundaries, some of the rivers, districts and the study locations.

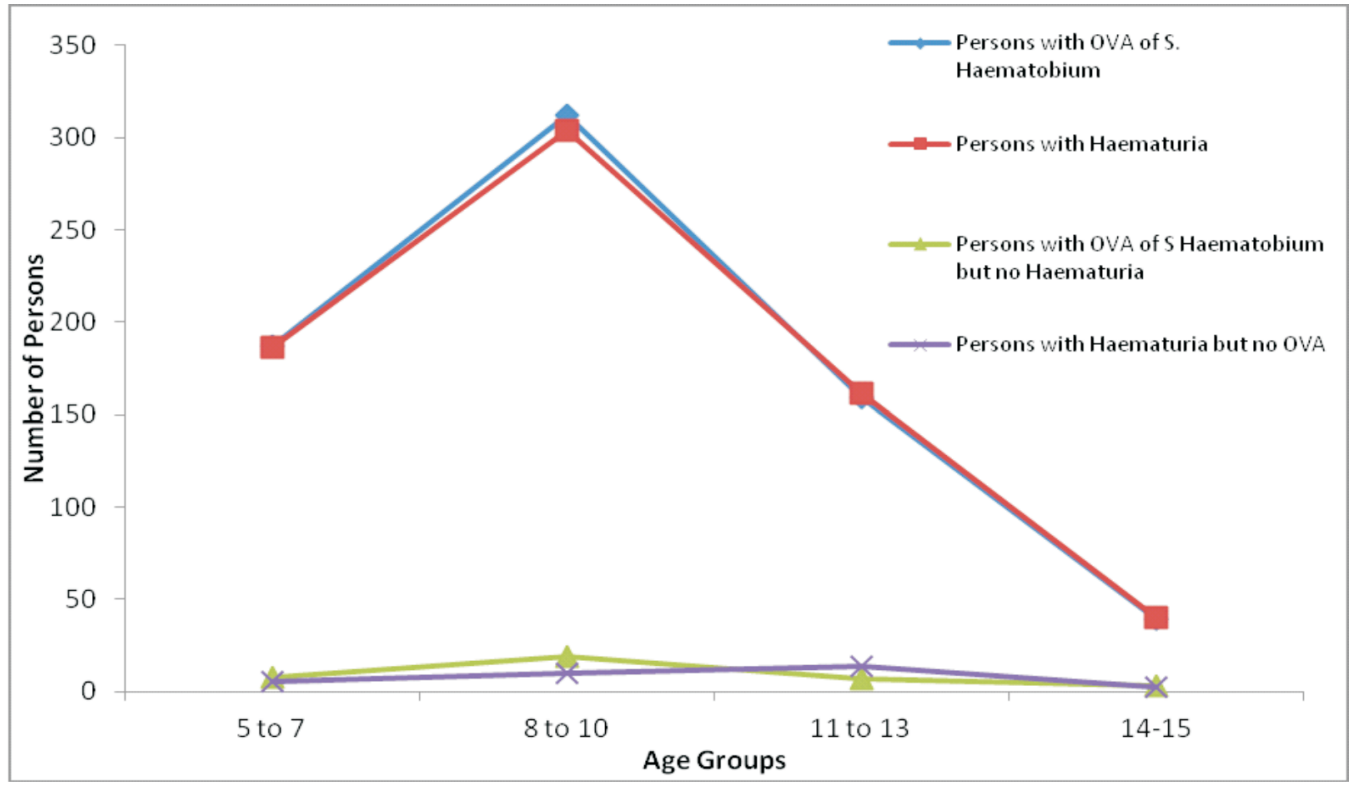

Figure 2: Respondents with ova of S. Haematobium and Haematuria in each age group 